\title{
A literatura infantil e alimentação saudável com foco na memória sensorial ${ }^{1}$
}

\author{
Sofia Regina Paiva Ribeiro² \\ Francisco Domiro Ribeiro Filho ${ }^{3}$
}

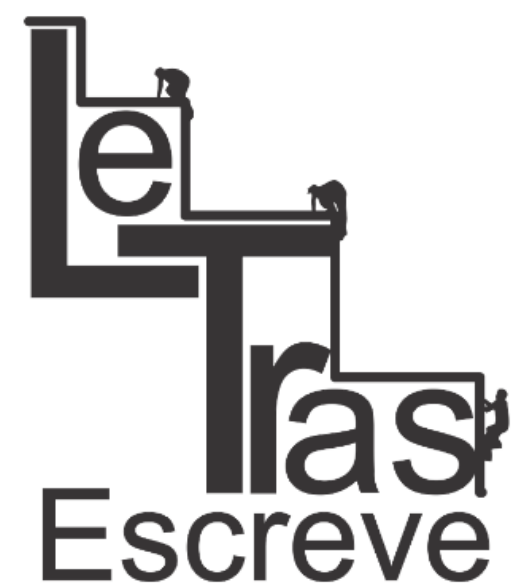

(ISSN 2238-8060)

\begin{abstract}
Resumo: Este trabalho tem como finalidade fazer um ensaio sobre a educação alimentar e nutricional no contexto da literatura infantil, destacando os elementos que norteiam a sua prática. A pesquisa está norteada por referenciais teórico-metodológicos que colocam em evidência a temática. Ressalta-se o rito da comensalidade e sua relevância nas práticas saudáveis na infância, como ainda a influência da memória gustativa e as características sensoriais no contexto alimentar na vida adulta. Assim, defende-se que o letramento e as boas práticas alimentares têm um papel primordial para a construção do identitário sociocultural. Dessa forma, propõem-se uma reflexão sobre a educação alimentar e nutricional no contexto empírico do lar e o efeito que a prática da leitura, com propósito, exerce na formação dos valores e escolhas do indivíduo durante seu ciclo de vida.
\end{abstract}

Palavras-chaves: Alimento. Livro. Família. Sensorial. Educação.

\section{ABSTRACT}

This work aims to make a test on food and nutrition education in the context of children's literature, and highlight the elements that guide their practice. The research is guided by theoretical and methodological frameworks which stress the theme. It emphasizes the rite of edibility and its relevance in healthy practices in childhood, but also the influence of gustatory memory and sensory characteristics in the food context in adulthood. Thus, it is argued that literacy and good dietary practices have a key role in the construction of socio-cultural identity. Thus, we propose a reflection on the food and nutrition education in the empirical home context and the effect that the practice of reading with purpose, plays in the formation of values and choices of the individual during their life cycle .

Keywords: Food. Book. Family. Sensory. Education.

\section{Introdução}

A criança é um ser em construção que a cada dia busca novas informações. Esse processo contínuo também ocorre com a

\footnotetext{
1 Estudo desenvolvido com apoio da Fundação Cearense de Apoio ao Desenvolvimento Científico e Tecnológico - FUNCAP.

2 Mestranda em Sociobiodiversidade e Tecnologias Sustentáveis (UNILAB), Especialista em Gestão da Educação Pública (UFMG), Informática Educativa (UECE), Mídias na Educação (UFC), Licenciada em Letras (UECE), e-mail: sofiarpr@gmail.com.

${ }^{3}$ Licenciado em Química e biologia (UECE), Bacharel em Direito (UCRS) e Especialista em Direito Processual Civil e Penal (Faculdade Kurios) email.dmpr2006@ig.com.br
} 


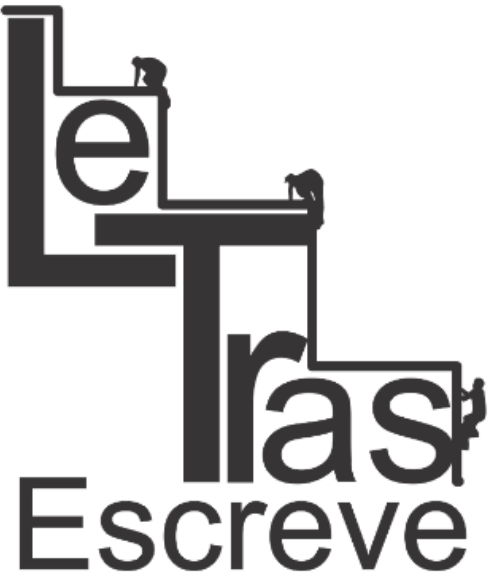

(ISSN 2238-8060)

memória gustativa. A formação do comportamento alimentar faz parte da nossa personalidade, da nossa identidade social, e são hábitos adquiridos na infância, trazendo consigo traços multidimensionais, entre eles, culturais, religiosos e familiares, ou seja, o ato de alimentar-se vai além de satisfazer somente nossas necessidades vitais de sobrevivência.

Nesse foco, cabe evidenciar a importância da prática de uma alimentação saudável, que deve ser estimulada desde cedo. Outro ponto a ser defendido é a literatura voltada às boas práticas alimentares, que tem uma forte influência na formação da memória gustativa das crianças.

Observa-se que o apelo visual na literatura infantil reporta de uma forma muito clara a relevância em que a alimentação é citada nos livros. Depara-se com essa asserção em alguns clássicos, como exemplo, Chapeuzinho Vermelho, em que a neta tem a missão de levar um cesto repleto de doces para a vovozinha doente. O imaginário infantil em desenvolvimento é construído, também, pelo exercício da imaginação, um papel relevante no processo de ensino e aprendizagem que pode ser formal ou informal.

Vygotsky (1994, p. 88) pondera que

\begin{abstract}
Em estudos experimentais sobre o desenvolvimento do ato de pensar em crianças em idade escolar, tem se admitido que processos como dedução, compreensão, evolução das noções de mundo, interpretação da casualidade física, o domínio das formas lógicas de pensamento e o domínio da lógica abstrata ocorrem por si mesmas, sem nenhuma influência do aprendizado escolar.
\end{abstract}

Isto posto, percebe-se que a infância é um período em que o ser humano está começando a leitura de mundo, ou seja, exercitando a educação informal. É nessa fase também que surgem os primeiros contatos com os sabores a influenciarem nos nossos gostos e opções alimentares. Daí destacar a relevância do ambiente familiar na formação do padrão alimentar.

https://periodicos.unifap.br/index.php/letras

Macapá, v. 6, n. I, Io semestre, 2016. 
Com esse norte, o presente estudo volta-se para a necessidade da construção de hábitos salutares de nutrição, ressaltando a valia da literatura infantil na abordagem da temática. Entende-se que o estimulo a leitura associada a contexto voltados para uma alimentação equilibrada são valores que ficam, de forma intrínseca, presente nas escolhas do indivíduo quando adulto.

Considerando a relevância dos fatores nutricionais e sensoriais associados à alimentação oferecida às crianças, decidiuse por analisar os aspectos da literatura alimentar no âmbito da formação da memória gustativa. Convém esclarecer, em primeira apreciação, que uma alimentação saudável deve ser quantitativamente suficiente, harmoniosa nos componentes, adequada à sua finalidade e ao organismo a que se destina, para que se possa obter saúde e qualidade de vida (CREDIDIO, 2008).

Conforme o Ministério da Saúde, órgão do Poder Executivo Federal responsável pela organização e elaboração de planos e políticas públicas voltados para a promoção, prevenção e assistência à saúde dos brasileiros (Brasil, 2008; pág. 41), as

[...] refeições são saudáveis quando preparadas com alimentos variados, com tipos e quantidades adequadas às fases do curso da vida, compondo refeições coloridas e saborosas que incluem alimentos tanto de origem vegetal como animal.

(ISSN 2238-8060)

Dada a importância do tema, defende-se que a educação alimentar começa em casa logo nos primeiros dias vida, quando as escolhas alimentares dos pais são atentamente acompanhada pelos filhos. Segundo Vygotsky, a criança reproduz o comportamento social dos pais, isto porque ela tem como necessidade a reprodução do cotidiano do adulto, seu exemplo diário e mais próximo de aprendizagem.

Seguindo o mesmo princípio, surge o despertar pelo interesse literário, através do processo da contação de histórias, quando a criança aguça o imaginário e inicia-se no processo de letramento. Nesse sentido, Abramovich (2003) defende que "ouvir e ler histórias 


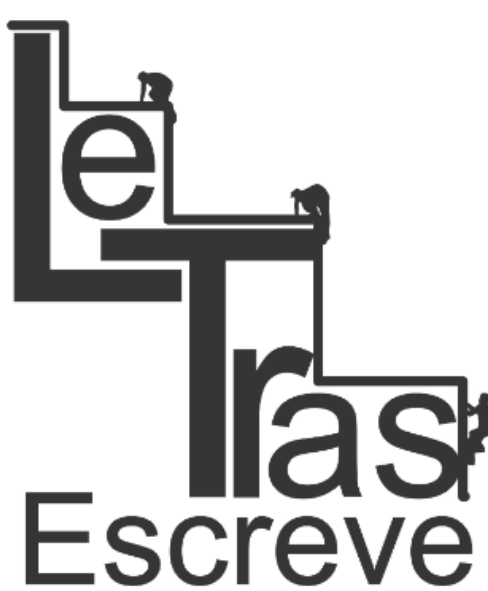

(ISSN 2238-8060) é também desenvolver todo o potencial crítico da criança. É poder pensar, duvidar, se perguntar, questionar...".

De acordo com Martins (1986), os primeiros contatos com o mundo são também os primeiros passos para aprendermos a ler. Dessa forma, a leitura de histórias, fábulas e contos de fadas favorecem o desenvolvimento psíquico da criança. Ao ouvi-los, elas assimilam lições e formam valores. Depreende-se que a leitura de história, como hábito, permite a formação de um leitor atento e sensível, e capaz de compreender e interpretar textos.

Entre as várias indagações, optou-se por verificar: 1) como os hábitos dos personagens das histórias infantis influenciam às crianças?; 2) como fortalecer a memória gustativa das crianças através da literatura infantil?; 3) qual o papel da família no contexto da educação alimentar?

Para a realização desse trabalho de pesquisa descritiva e exploratória, optou-se por uma investigação em livros, artigos, periódicos, revistas e documentos que abordam a temática. Entre os autores, explorou-se algumas obras de Paulo Freire (1989), Vygotsky (1994), Abramovich (1973) e Silva (2003) entre outros.

\section{O Mundo da Imaginação}

A leitura tem um papel primordial no imaginário infantil, os objetos da leitura ganham cor, forma e significado no imaginário do ouvinte/expectador. Observa-se que o ato de contar histórias é uma atividade importantíssima para a transmissão de valores humanos. É uma ação simples, mas de um valor inestimável. Feita com frequência, e através da interação entre leitor e ouvinte, ensina de forma lúdica e prazerosa.

Ao lembrar da história de João e Maria, conto de fadas de tradição oral e que foi coletado pelos irmãos Grimm, vem logo em nossa mente uma casa cheia de doces, repleta de atrativos para as crianças, que, de acordo com o enredo da história, estavam

https://periodicos.unifap.br/index.php/letras Macapá, v. 6, n. I, Io semestre, 2016. 
famintas e perdidas na floresta. Ao ouvir a narrativa, a criança vislumbra o ambiente com uma riqueza de detalhes, imagina os objetos com suas características, cores, texturas e tamanho e relevância.

Nesse sentido, relatam os PCN's (2001, p.54.):

Um leitor competente é alguém que, por iniciativa própria, é capaz de selecionar, dentre os textos que circulam socialmente, aqueles que podem atender a uma necessidade sua. Que consegue utilizar estratégias de leitura adequada para abordá-los de forma a atender a essa necessidade.

Em conformidade com a citada transcrição, percebe-se que a fantasia, a magia, a imaginação e todo o mistério que envolvem o ato da leitura criam uma ação/reação para o ouvinte (ou leitor). No

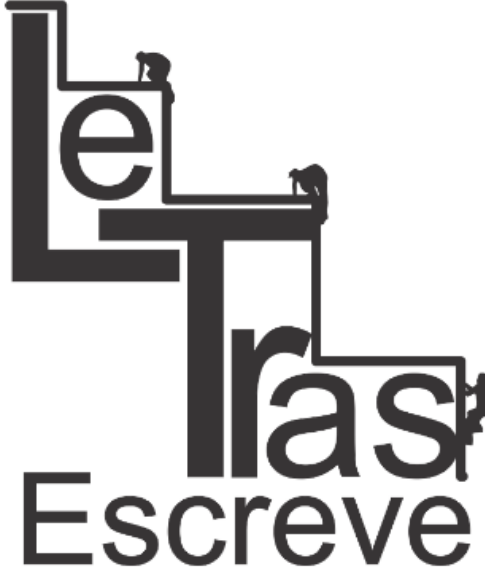

(ISSN 2238-8060) caso da criança, que está em fase de descoberta e constante aprendizagem, essa estratégia de leitura tem um relevante papel formador. Assim, é valido afirmar que a literatura infantil propicia significativamente o desenvolvimento social, emocional e cognitivo da criança.

Quando a criança ouve ou lê uma história, torna-se capaz de comentar, indagar, duvidar ou discutir sobre ela, realizando uma interação verbal sobre o contexto abordado (BAKHTIN, 1997).

O primeiro contato que a criança tem com o "mundo das letras" é através das narrações feitas, geralmente, pelos pais. Dessa forma, o ato da leitura não deve ser visto como uma obrigação. O prazer proporcionado pelas estórias é adquirido através de estímulos da contextualização das narrações. Para tanto, o adulto precisa interagir e incentivar a criança desde cedo, para que ela sinta-se familiarizada e posteriormente passe a ter a leitura com hábito. Conforme Silva (1992, p.57) "bons livros poderão ser presentes e grandes fontes de prazer e conhecimento. Descobrir estes sentimentos desde bebezinhos, poderá ser uma excelente conquista para toda a vida." 


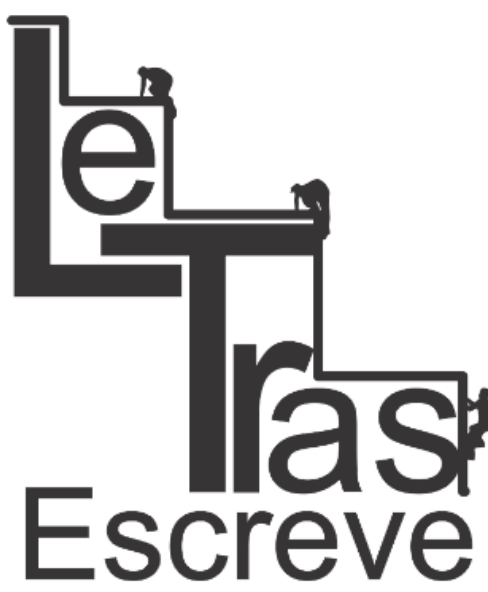

(ISSN 2238-8060)

Somos frutos do meio, o hábito da leitura direcionada à educação alimentar e às boas práticas alimentares traz vários benefícios para o indivíduo na infância, vindo consequentemente refletir na vida adulta. Observa-se que as características sensoriais inerentes à alimentação estão presentes em nosso cotidiano e influenciam diretamente nas nossas escolhas diárias. As alternâncias de hábitos alimentares na fase adulta não é uma tarefa fácil, requer mudanças de paradigmas. A alimentação interfere nas relações sociais, na qualidade de vida e na produtividade (ABREU et al., 2001; ALEVATO; ARAÚJO, 2009).

Isto posto, entende-se que inserir temas que tratam o contexto alimentar e proporcionar práticas alimentares saudáveis são de suma importância para a formação da memória gustativa do indivíduo. Conforme as Diretrizes da Política Nacional de Alimentação e Nutrição (2013, pág. 7) a população brasileira, nas últimas décadas, experimentou grandes transformações sociais que resultaram em mudanças no seu padrão de saúde e consumo alimentar.

Oportuno relevar, em complemento, que alimento e comida não são sinônimos. Segundo Da Matta (1986) "Toda substância nutritiva é alimento, mas nem todo alimento é comida. Já de acordo com Santos (2004) alimentar-se é um ato nutricional, comer é um ato social, pois constitui atitudes ligadas aos usos, costumes, protocolos, condutas e situações. Assim, infere-se que o ato de comer muitas vezes não contempla, na totalidade, o contexto nutritivo que nosso organismo precisa.

A nutrição é importante para todos, independentemente da idade, mas na infância é fundamental. $O$ estimulo à boa alimentação pode/deve fazer parte de uma educação alimentar. A interação familiar relacionada as boas práticas alimentícias é essencial para a saúde e a construção da memória gustativa. A esse respeito assevera Viana et al (2008) que "a criança aprende, desde muito 


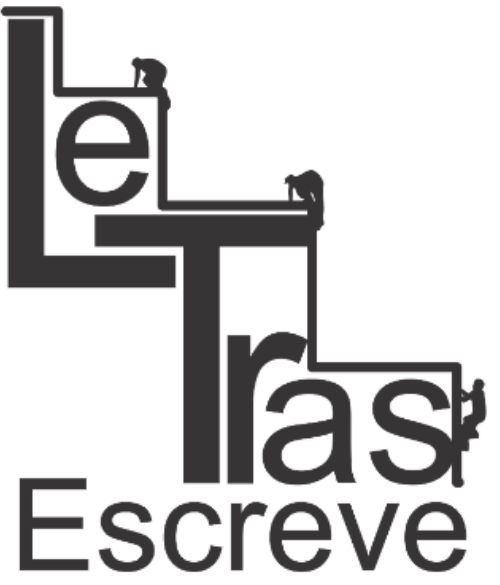

(ISSN 2238-8060)

cedo, o significado cultural e social dos alimentos, desenvolvendo deste modo preferências e rejeições".

A criança é um ser em construção, são nos primeiros anos de vida (na infância) que estão as vivências decisivas para a formação da personalidade do indivíduo, sua formação de crenças e valores. Defende-se que a leitura tem um papel relevante no contexto educacional, mas somos sabedores que os filhos são espelho dos pais. Dessa forma os atos/ações oriundos dos pais atuam psiquicamente de modo marcante no comportamento da criança. Daí a clássica e sábia frase "ensina-se com palavras, mas educa-se com exemplos".

A educação pelo exemplo acontece no cotidiano, são pequenas atitudes que fazem a diferença. Estudos comprovam que filhos de leitores assíduos têm mais chance de desenvolver o hábito da leitura. Desta maneira, para que a criança adquira hábitos saudáveis, como a leitura e alimentação adequada, faz-se necessário que a família esteja engajada.

\section{O Processo de Letramento}

Sabe-se que o processo de ensino e aprendizagem começa no âmbito familiar. Preleciona Paulo Freire (1989), em seu livro a "Importância do Ato de Ler", que a leitura do mundo precede a leitura da palavra. Enquanto a alfabetização se ocupa da aquisição da escrita por um indivíduo, ou grupo de indivíduos, o letramento focaliza os aspectos sócio-históricos da aquisição de uma sociedade (Tfouni, 1995, p. 20).

Letramento é uma tradução para o português da palavra inglesa "literacy", cujo significado é a condição de ser letrado. Alfabetização e letramento têm características bem distintas.

O processo de alfabetização preocupa-se com a decodificação dos signos linguísticos, ou seja, sabe ler e escrever; já o letramento é mais complexo, pois o indivíduo adentra no mundo da 
leitura e da escrita, com a habilidade de entender de forma adequada a demandas social inerente ao processo de leitura e escrita.

Defende-se que o conhecimento das letras é apenas um meio para o letramento, que por sua vez, é o uso social da leitura e da escrita. Percebe-se que até pouco tempo havia um modelo padrão de alfabetização, pautado na decodificação dos signos. De acordo com Cagliari (1998, p. 15),

$\mathrm{Na}$ antiguidade, os alunos alfabetizavam-se aprendendo a ler algo já escrito e depois copiado. Começavam com palavras e depois passavam para textos famosos, que eram estudados exaustivamente. Finalmente, passavam a escrever seus próprios textos. O trabalho de leitura e cópia era o segredo da alfabetização.

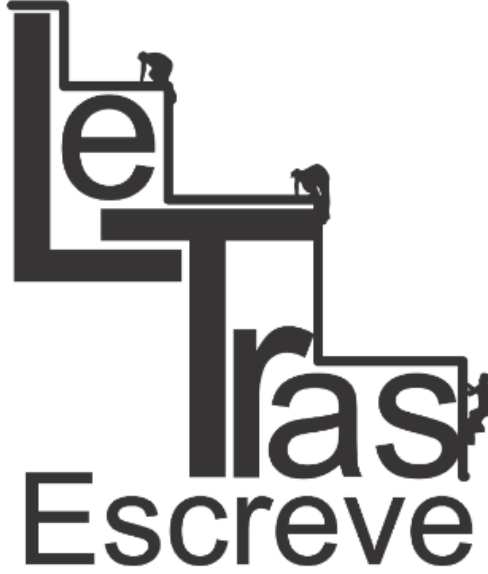

(ISSN 2238-8060)

Já o letramento inicia-se bem antes da alfabetização, nos primeiros contatos da criança com o contexto social e com práticas de leitura. Face ao exposto, depreende-se que o letramento é assimilado através de uma vivência cultural. Entende-se que a criança deve ter contato com o mundo das letras no ambiente familiar, e que ao chegar à escola já conhece/entende a relevância do letramento. Dessa forma, o aprendizado deixa de ser um ato automático e repetitivo, e passa a ser vislumbrado como um processo prazeroso de interação com o mundo.

Acredita-se que a criança deve ter uma proximidade desde cedo com o mundo dos livros. A prática de contação de histórias e o contato físico com o objeto cheios de atrativos visuais (cores vibrantes, efeito 3D, desenhos...) são indispensáveis para desenvolver na criança o hábito e o gosto pela leitura.

As etapas de conhecer as gravuras e interpretar as figuras propiciam a formação de uma sequência lógica que fortalecer e estimula o imaginário da criança. Na contação de história, o ouvinte a absorve e passa a sentir-se parte dela, a envolver-se com o enredo e ser capaz de opinar e defender seu ponto de vista. 
Segundo Abramovich (1993, p.16), a contação de histórias é o primeiro contato da criança com um texto

Ah, como é importante para a formação de qualquer leitor ouvir muitas, muitas histórias... Escutá-las é 0 início da aprendizagem para ser um leitor, e ser leitor é ter um caminho absolutamente infinito de descoberta e de compreensão do mundo.

Outra prática de formação do leitor é a entrega de um livro cheio de atrativos visuais para uma criança, que não sabe ler, que é fundamental para despertar o interesse pelo o entendimento da sequência lógica das gravuras e da decodificação dos signos linguísticos. Para tanto, o livro deve ser uma fonte de diversão, um passaporte para o mundo mágico da ação e emoção.

Por fim, defende-se que entre as várias habilidades desenvolvidas por meio da literatura, entre elas a ampliação do vocabulário, optou-se por buscar fortalecer a memória gustativa através de temas que abordem uma alimentação saudável, gostosa e nutritiva. Em que frutas e verduras possam ser amigos imaginários das crianças. Segundo Da Matta (1986, pág 22)

\begin{abstract}
Alimento é algo universal e geral. Algo que diz respeito a todos os seres humanos: amigos ou inimigos, gente de perto e de longe, da rua ou de casa, do céu e da terra. Mas a comida é algo que define um domínio e põe as coisas em foco. Assim, a comida é correspondente ao famoso e antigo de-comer, expressão equivalente a refeição, como de resto é a palavra comida. Por outro lado, comida se refere a algo costumeiro e sadio, alguma coisa que ajuda a estabelecer uma identidade, definindo, por isso mesmo, um grupo, classe ou pessoa. (Da Matta,4p.22)
\end{abstract}

Alimentar-se bem vai muito além da necessidade física nutricional. Defende-se que as refeições são atos socializantes e muitos dos nossos hábitos alimentares são adquiridos nos primeiros anos de vida ao lado da família. Prezar por uma alimentação saudável durante a infância é essencial para o desenvolvimento e a

https://periodicos.unifap.br/index.php/letras

Macapá, v. 6, n. I, Io semestre, 2016. 
prevenção de problemas de saúde ligados a má alimentação, entre elas a obesidade.

\section{O contexto tecnológico e a prática da leitura}

O período contemporâneo está cheio de atrativos tecnológicos, onde a informação, a cada dia, torna-se mais interativa e descartável. O uso das mídias de informação e comunicação ganham espaço em todos os ambientes da sociedade. Em nossa casa (nosso lar) não é diferente. Cedo a criança é inserida no contexto tecnológico da interação, um mundo cheio de atrativos visuais e sonoros. É nesse ambiente diversificado e chamativo que o livro parece perder espaço para as facilidades tecnológicas.

A este respeito, Emília Ferreiro relata, numa palestra em São

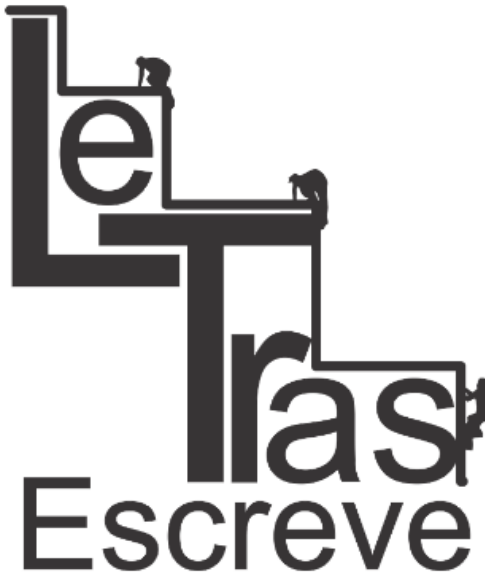

(ISSN 2238-8060)

Graças às Novas Tecnologias, talvez seja mais fácil introduzir a criança à cultura letrada. As Novas Tecnologias são muito poderosas e não tem sentido perguntar se são boas ou más, se servem ou não. A cada dia há mais escolas conectadas em rede, tudo indica que o acesso à Internet vai se proliferar como aconteceu com o celular.'(FERREIRO, 2008)

Vive-se na sociedade da informações e comunicação, "o mundo virtual" faz parte da realidade do "mundo real". O advento da internet trouxe uma infinidade de atrativos para as crianças, entre eles, pode-se citar os jogos, com seus apelos sonoros e um misto de cores e luzes. Num mundo globalizado, que derruba barreiras de tempo e espaço, o acesso à tecnologia exige atitude crítica e inovadora, possibilitando o relacionamento com a sociedade como um todo (BEHRENS, 2000, p. 77)

Dessa forma, fica a preocupação dos pais em acompanhar e direcionar essa ferramenta tão poderosa e interativa que a cada dia ganha mais espaço em nosso contexto sociocultural. Sabe-se que 


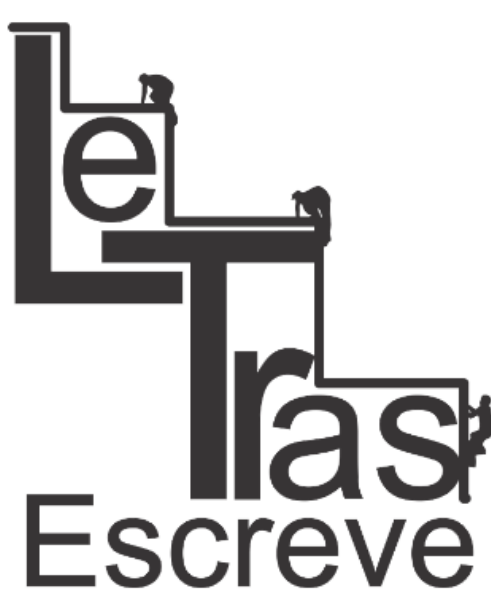

(ISSN 2238-8060) muitos softwares são voltados para o contexto da informática educativa, e que o uso do computador pode ser vislumbrado como uma ferramenta pedagógica que auxilia no processo de construção do conhecimento. Sim, um auxilio, pois defende-se que o uso das Tecnologias de Informação e Comunicação são um meio e não um fim.

Com o advento da internet, a criança fica exposta a uma quantidade excessiva recursos e informações, em desacordo seu ritmo de aprendizagem, idade e maturidade que devem sempre ser respeitados e delimitados, pois, para Lorenzato (1991), o uso de qualquer recurso depende do conteúdo a ser ensinado, dos objetivos que se deseja atingir e da aprendizagem a ser desenvolvida, visto que a utilização de recursos didáticos contribui na construção do conhecimento.

Dessa forma, o livro exsurge como um recurso didático fascinante, e não é à toa que é considerado, por muitos, como uma das maiores invenções da humanidade. Bons livros ajudam a desenvolver o senso crítico; a capacidade de ler e entender o mundo ao nosso redor. O hábito da leitura permite a formação de juízo de valores, ou seja, escolhas por meio de parâmetros concretos de conhecimento, através da capacidade de discernir entre o simples e o complexo, certo e errado.

Especialistas defendem que, para alguém se interessar por livros na vida adulta, é fundamental que a palavra escrita esteja ao seu alcance desde cedo, e a literatura infantil está recheada de opções para encantar os futuros leitores: são livros feitos de pano (que podem servir de travesseiro), livro de plástico (companhia para a hora do banho), livros musicais (para embalar o sono), livros com tecnologia 3D - um recurso que permite visualizar detalhes e construir belas estórias, e por fim, livros com estórias e Histórias que encantam o imaginário infantil.

Para Elias (2007, pag. 22): 
Há livros para se conhecer palavras, a realidade regional ou o mundo histórica e geograficamente, para se conhecer as artes, os sabores da boa cozinha, para se calcular, para analisar, para comprar, para nos ajudar, para nos esclarecer, conscientizar, para fazer a nossa cabeça ou levantar questões apenas, para nos passar técnicas de bem fazer algo, para fazer rir e chorar.

Nesse sentido, os livros com a temática alimentação saudável pode/deve ser inserida no acervo dos leitores ou futuros leitores. Como exemplo, quando a criança começa a ler e a entender que a frutas e verduras são coloridas e gostosas, será consequentemente estimulada a priorizar alimentos naturais e cheios de nutrientes em sua refeição.

\section{Considerações finais}

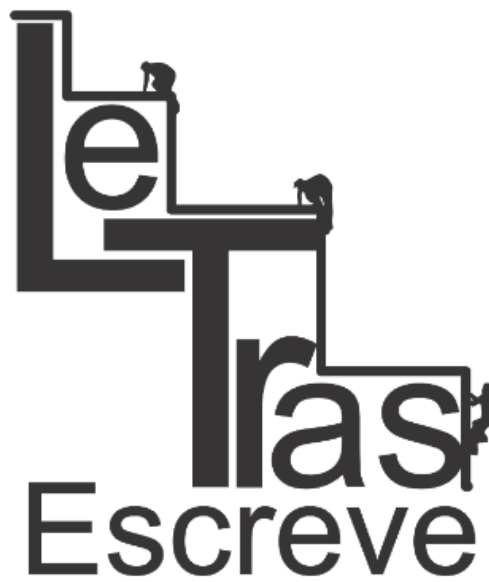

(ISSN 2238-8060)

Sabe-se que a educação alimentar e nutricional está vinculada à memória gustativa e às informações que, de uma forma direta ou indireta, são assimiladas na infância, e influenciarão seus gostos alimentares no decorrer da sua vida adulta. Para melhor assimilação, é imprescindível aprofundar a discussão sobre a relevância da educação alimentar associada ao contexto da literatura infantil, e sua contribuição para a saúde.

A leitura deve ser "recheada" de atrativos sensoriais, como textura e cores, permitindo ao leitor vislumbrar que o alimento pode ser ao mesmo tempo nutritivo e saboroso. Não só a leitura, mas sua associação a boas práticas alimentares ajudarão a formar paradigmas que consolidarão os hábitos alimentares na vida adulta.

$\mathrm{Na}$ literatura infantil, temas como alimentação saudável e educação alimentar na infância não são muito frequentes nas indicações literárias. É preciso ressaltar que a intenção não é desmerecer o valor dos grandes clássicos da literatura infantil, com seus príncipes, princesas, fadas, bruxas, doendes... são romances, fábulas, contos... muito presentes no imaginário infantil. 
Isto posto, livros como ACHAZ no Sítio da Banana Perdida ${ }^{4}, A$ menina que não gostava de fruta ${ }^{5}$, Hora do almoço ${ }^{6}$, O Reino encantado dos alimentos ${ }^{7}$ (eBook), a Turma da Mônica em Alimentos Saudáveis ${ }^{8}$ e a Coleção no Reino da Frutolândia ${ }^{9}$. São dicas de livros que retratam a temática de uma forma interativa. Onde a criança aprende o valor da alimentação equilibrada.

A Coleção no Reino da Frutolândia é composta por dez livros, publicada pela editora Letra Viva, escrita por Simoni Conceição Rodrigues Claudino, que é Professora de Educação Infantil. Ali as histórias são narradas por quatro crianças: Pedrinho, Aninha, Vanessa e Marcelinho - personagens principais do enredo. Esses livros trazem um quadro nutricional das frutas, a sugestão de uma receita e cuidados com a higiene.

Por fim, "A Literatura infantil e alimentação saudável: com foco na memória sensorial" aborda a indiscutível participação da família no processo de formação da criança, e sua influência para vida adulta. Os pais são modelos para os filhos e devem colaborar para a formação de um ser mais consciente, saudável e criterioso nas suas escolhas.

\section{Referências bibliográficas}

ABRAMOVICH, Fanny. Por uma arte de contar histórias. Disponível em:

\footnotetext{
4 Autores: Renato De Oliveira Caleffi | Alexandre Carvalho Editora Viajante do Tempo

${ }^{5}$ Autora: Cidália Fernandes - Ilustração: Sandra Serra - Editor: Edições Livro Directo

${ }^{6}$ Autor: Brenman, Ilan - Ilustração: Zilberman, Lonit - Editora: Cia Das Letrinhas

${ }^{7}$ Autor: Mauro Gonçalves Rueda - Versão para eBook eBooksBrasil.org

${ }^{8}$ Autor: Mauricio de Sousa (Ilustração) - Editora: Maurício de Sousa.

${ }^{9}$ A coleção No reino da frutolândia, volumes 1 e 2, escritos por Cristina Marques e Angela Rhod, é composta por dez livros cada volume, publicada pela editora Letra Viva.
} 
http://www.docedeletra.com.br/semparar/hspfanny.html>. Acessado em: 29 mai. 2016.

. Literatura infantil: gostosuras e bobices. 3.ed. São Paulo:

Scipione, 1993, 174 p. . (Pensamento e ação no magistério, 7)

ABREU, E. S. de; VIANA, I. C.; MORENO, R. B.; TORRES, E. A. F. da S. Alimentação mundial-uma reflexão sobre a história. Saúde e Sociedade. 10(2):3-14, 2001.

BAKHTIN, M. Estética da criação verbal. 4ed. São Paulo: Martins Fontes, 1997.

BEHERENS, Marilda Aparecida. Projetos de aprendizagem colaborativa num paradigma emergente. In.: MORAN, José Manuel. Novas tecnologias e mediação pedagógica. Campinas: Papirus, 2000.

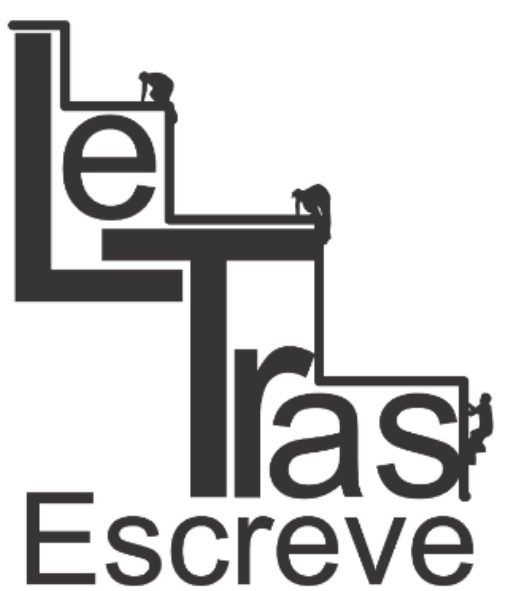

(ISSN 2238-8060)

BRASIL. Ministério da Educação e do Desporto. Secretaria de Educação Fundamental. Referencial curricular nacional para a educação infantil. Brasília, MEC/SEF, 1998.

CAGLIARI, Luiz Carlos. Alfabetizando sem o Bá-Bé-Bi-Bó-Bu: Pensamento e Ação no Magistério. 1. Ed. São Paulo: Scipione, 1998.

CREDIDIO, E. V. Alimentos Funcionais na Nutrologia Médica. Itu: Editora Ottoni, 2008, $4^{\circ}$ Edição.

DA MATTA, R. O que faz o Brasil, Brasil?. Rio de Janeiro: Rocco; 1986.

ELIAS, José. Literatura Infantil: ler, contar e encantar criança. Porto Alegre, Mediação, 2007.

FERREIRO, Emilia. Valoriza as novas Tecnologias. Disponível em http://www.planetaeducacao.com.br/ambientevirtual/conteudo/conteu domensagem.asp?ID POSTAGEM=119\&siteArea=64\&assuntoid=41 . Acesso em 26 mai 2016.

FREIRE, P. A importância do ato de ler: em três artigos que se completam / Paulo Freire. - São Paulo: Autores Associados: Cortez, 1989 
KRAEMER, Maria Luiza. Histórias e o Lúdico encantam as crianças. São Paulo. Autores associados LTDA, 2008

LORENZATO, S. Porque não ensinar geometria? Educação

Matemática em Revista. Sociedade brasileira em Educação Matemática - SBEM. Ano III. $1^{\circ}$ semestre 1995.

MARTINS, Maria Helena. O que é leitura. São Paulo: Editora Brasiliense, 1986.

SILVA, Ana Araújo. Literatura para Bebês. Revista Pátio. São Paulo, n.25, p. 57 59,Fev/Abr. 2003.UNESCO. Disponível em http www. unesco.gov.br. Acesso em 25 de mai 2016.

VYGOTSKY, L. S. A Formação Social da Mente. São Paulo: MARTINS FONTES, 1994.

Recebido em 13/07/2016. Aprovado em 20/08/2016.

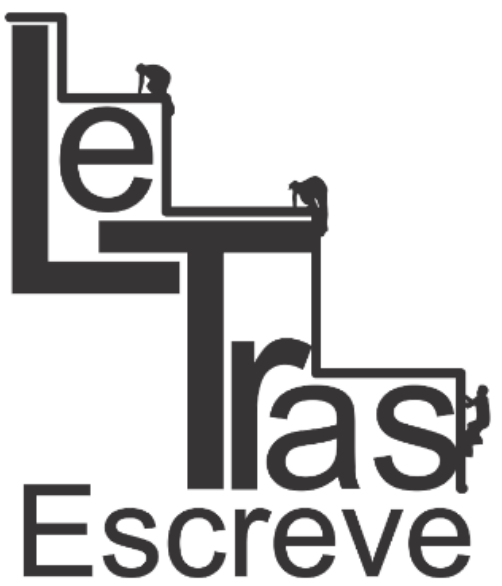

(ISSN 2238-8060) 